\title{
Analysis of Ventilation Efficiency and Effective Ventilation Flow Rate for Wind-driven Single-sided Ventilation Buildings
}

\author{
Junli Zhou ${ }^{1 *}$, Yong Hua ${ }^{1}$, Yuan Xiao ${ }^{1}$, Cheng $\mathrm{Ye}^{1}$, Wei Yang ${ }^{2}$ \\ ${ }^{1}$ School of Civil Engineering and Architecture, Wuhan University of Technology, Wuhan, \\ 430070, China \\ ${ }^{2}$ Faculty of Architecture, Building and Planning, The University of Melbourne, Melbourne, 3010, \\ Australia
}

\section{ABSTRACT}

Natural ventilation can be categorized into single-sided ventilation and cross-ventilation. Based on the air flow mechanism of a single-sided wind-driven natural ventilation, the effective ventilation flow rates in buildings are different from the air flow rates through openings. The mixing coefficient or ventilation efficiency is defined by the ratio of these flow rates, indicating the effective ventilating ability of a single-sided ventilation, similar to the effect of penetration depth of fresh air. This paper provides a detailed analysis of ventilation effectiveness in a building with a single opening based on numerical simulations. The simulation was validated by a study of an existing case. By numerical calculation, the air flow rates through openings and the effective ventilation flow rates in buildings were compared. Effects of various influencing parameters, such as wind speed, opening location, opening area and aspect ratio of windward wall on ventilation efficiency were evaluated. An estimated mixing coefficient has been established by the modelling, which would be beneficial for the predication of the short-circuit ratio of ventilation rate through openings.

Keywords: Single-sided ventilation, Ventilation efficiency, Effective ventilation rate, Numerical simulation

\section{INTRODUCTION}

Received: August 1, 2020

Revised: October 25, 2020

Accepted: December 12, 2020

${ }^{*}$ Corresponding Author:

jlzhou@whut.edu.cn

\section{Publisher:}

Taiwan Association for Aerosol Research

ISSN: $1680-8584$ print

ISSN: 2071-1409 online

(c) Copyright: The Author(s). This is an open access article distributed under the terms of the Creative Commons Attribution License (CC BY 4.0), which permits unrestricted use, distribution, and reproduction in any medium, provided the original author and source are cited.
Due to the demand for the lowering energy consumption and reducing greenhouse gas emissions, there have been increasing attention by the building industry and research academics on passive technology of natural ventilation for buildings (Yik and Lun, 2015; Abdullah and Alibaba, 2020), when the outdoor ambient air is suitable. For ordinary residents, natural ventilation is the major technology to improve the indoor thermal environment.

However, the application of natural ventilation should be limited when outdoor ambient air is badly polluted or there might be an issue regarding transmission of pathogenic viruses. For example, transmission of pathogenic viral disease could occur between close neighbouring buildings due to ventilation (Wang et al., 2010). Residents living close to an infected shelter or hospital might worry about the possibility of coronavirus transmission by air flow during the epidemic period. In either case, the natural ventilation of buildings should be considered and analyzed carefully (Xu et al., 2020).

Natural ventilation can be divided into two categories - wind-driven ventilation and stackeffect ventilation, according to different driven forces (Haw et al., 2012; Aflaki et al., 2015; Bai et al., 2015; Wang et al., 2020). It also can be classified into single-sided ventilation and cross ventilation according to different locations of ventilation at the same time (Ai et al., 2011; Jin et al., 2016; Wang et al., 2018; Park et al., 2020). 
Cross ventilation can provide large air-exchange rate in comparison with single-sided ventilation (Fung and Lee, 2015). However, only a few buildings can be designed to utilize cross ventilation because of room depth, interior partitions and other obstacles in most cases. Consequently, unilateral ventilation is also very common in building design (Wang and Chen, 2012; Aflaki et al., 2016; Ai and Mak, 2018), which would require further considerations.

The flow characteristics of single-sided ventilation are complex because of the fluctuating effect of the air flow around buildings and openings. Over the past years, Warren and Parkins (1977), De Gids and Phaff (1982), Larsen and Heiselberg (2008), Wang and Chen (2012) had proposed different models to calculate the air flow rate driven by single-sided wind-driven natural ventilation, as is shown in Table 1. These models are popular and had been proven to be effective in a certain extent (Caciolo et al., 2011; Tang et al., 2016; Hayati et al., 2017; Pan et al., 2019).

In recent years, some researches about ventilation rate of single-sided ventilation have been carried out based on these previous models. For example, according to the wind-driven model of Wang and Chen (2012), Pan et al. (2019) developed a simple model for calculating the ventilation rate for an apartment residence with single-sided natural ventilation with buoyancy and wind pressure effects. Similarly, Zhou et al. (2017) put forward a single-sided ventilation rate model, which shows that the total flow rate is majorly decided by pulsating airflow with small opening, but it is mainly caused by the mean airflow when the opening area is large. The equation put forward by De Gids and Phaff (1982) had been used in in European standard EN 15242:2007, "prediction of air flows due to windows opening". In the revised European standard EN 16798$7: 2017$, a new version of the equation for the evaluation of the single-sided natural ventilation is given. Larsen found that the new simple direct calculation model given in EN 16798-7:2017 could predict airflows through windows in a more conservative way in comparison to equations given in the earlier version of the standard. The calculation model represents an average of the airflow rate in the building which is generally on the safe side (Larsen et al., 2018). Moreover, da Graça (2018) pointed out that the wind driven SS1 flows in small one zone buildings may be caused by static pressure change across the opening area, and he presented a calculation model considering turbulent mixing in SS1 flows. These models are very important for guiding the design of natural ventilation for a building due to the indoor temperature is thoroughly affected by air-exchange rate, especially the models that are given in Table 1.

However, the accuracy of these models is not the focus of this paper. These models do not refer to the same type of airflow rate. Therefore, some application result difference would be caused between them. There are basically two types, namely effective air change rates and air change rate through openings. The effective air flow rates are different from bulk airflow rates across openings. One of the reasons is that the air entering the room is not evenly distributed (Martins and da Graça, 2016). The ratio between the effective air flow rate and the bulk airflow rate across openings is defined as the mixing coefficient or ventilation efficiency (Cockroft and Robertson, 1976; Bu and Kato, 2016), which is the core research objective of this study.

\subsection{Ventilation Efficiency or Mixing Coefficient}

Generally, the concept of ventilation efficiency is often used to evaluate the ventilation

Table 1. Existing empirical models for the determination of single-sided ventilation rate.

\begin{tabular}{|c|c|c|c|}
\hline Reference & Equations & Technique & Air flow rates \\
\hline Warren and Parkins (1977) & $Q_{w}=0.25 A U_{r e f}$ & $\begin{array}{c}\text { Wind tunnel and full- } \\
\text { scale experiments }\end{array}$ & $\begin{array}{l}\text { Effective air } \\
\text { change rate }\end{array}$ \\
\hline Phaff and De Gids (1982) & $Q_{T}=\frac{1}{2} A \sqrt{D_{1} U_{10}^{2}+D_{2} H_{o} \Delta T+D_{3}}$ & Field test & $\begin{array}{l}\text { Effective air } \\
\text { change rate }\end{array}$ \\
\hline $\begin{array}{l}\text { Larsen and Heiselberg } \\
\qquad(2008)\end{array}$ & $Q_{T}=\frac{1}{2} A \sqrt{D_{1} f(\theta)^{2}\left|C_{p}\right| U_{r e f}^{2}+C_{2} H_{o} \Delta T+C_{3} \frac{\Delta C_{p} \Delta T}{U_{r e f}^{2}}}$ & $\begin{array}{l}\text { Wind tunnel } \\
\text { experiments }\end{array}$ & $\begin{array}{l}\text { Effective air } \\
\text { change rate }\end{array}$ \\
\hline Wang and Chen (2012) & $Q=\frac{C_{d} I \sqrt{C_{p}} \int_{z_{0}}^{H_{0}} \sqrt{z^{2 / 7}-z_{n}^{2 / 7}} d z}{z_{\text {ref }}^{1 / 7}} U_{\text {ref }}$ & Theoretical analysis & $\begin{array}{l}\text { Air change rate } \\
\text { through } \\
\text { opening }\end{array}$ \\
\hline
\end{tabular}


performance, especially in mechanical ventilation (Sandberg, 1981; Krajčík et al., 2012; Kabanshi et al., 2016). The ventilation efficiency can be generally calculated by local mean age of air or contamination concentration.

In the field of natural ventilation, the ventilation efficiency has been the subject of recent research interests. For example, Grabe et al. (2014) quantified and compared ventilation efficiencies of different types of windows under buoyancy ventilation. The horizontal pivot window was proved to be the best performing type of window due to high ventilation efficiencies. The influence of wind pressure is not considered in the study. Montazeri and Montazeri (2018) evaluated the effect of outlet openings on the ventilation characteristics in a one-room building, in which ventilation efficiency is one of indicator. It was concluded that the combination onesided wind catcher and window positioned on the leeward wall of the building is better than other outlet openings. The paper focuses on cross ventilation, not single-sided ventilation. Arinami et al. (2019) evaluated the ventilation performance by considering both the fresh-air arrival rate to the occupied zone and the effective air change rate, with a building model with two openings on one sidewall aligned parallel to the direction of the approaching wind.

Considering the wind-driven single-sided ventilation with one opening, the air flow inlet and outlet are at the same opening. Therefore, the ventilation performance is difficult to be evaluated by a measurement of the local contamination concentration. However, the ventilation performance also can be analyzed by effective ventilation rate and opening ventilation rate.

In 1976, Cockroft and Robertson (1976) propounded the concept of mixing coefficient. When the wind passed through the opening, the low-frequency variation in pressure would produce a pulsating airflow through the opening, which would be mixed with internal air in the enclosure. However, the other part would pass back out without mixing. This fraction is known as the mixing coefficient, which represents the ratio of the airflow rate through the opening that contributes to the effective air exchange. They concluded that only $37 \%$ of air change rate through the opening is mixed with the indoor air in a single-sided ventilation (Cockroft and Robertson, 1976). The building model has a very small opening area in their study. In 2008, Larsen and Heiselberg (2008) compared the effective ventilation volume with the airflow rate measured at the opening. The deviations were $10 \%$ and $20 \%$ respectively (Larsen and Heiselberg, 2008). In 2011, Bu and Kato (2016) defined the ventilation efficiency of the unilateral ventilation. The results show that the ventilation efficiency is $31.7 \%$ and $37.5 \%$ respectively in the case of windward and leeward airflows (Bu and Kato, 2016). However, like Bu expressed in his paper, the location and area of the opening would affect the ventilation effectiveness in a single-sided ventilation. Thus, further investigation is required in future work.

\subsection{Penetration Depth of Fresh Air}

Effective distribution of fresh air in the natural ventilated room is very important to ensure a comfortable thermal environment and high indoor air quality (Visagavel and Srinivasan, 2009). Similar to the mixing coefficient or ventilation efficiency, the penetration depth of fresh air would represent the effective ventilating ability of the natural ventilation. Usually, a bigger penetration depth for natural ventilation is required in a single sided apartment, as in the case of the natural lighting penetration. However, the opposite is truth in case of badly polluted outdoor air.

For cross natural ventilation due to wind, the ventilation effect is better than that of singlesided ventilation, and is of little significance to discuss the penetration depth of fresh air. However, for the single-sided ventilation, the inlet and outlet of fresh air are at the same opening, and the mechanism of indoor airflow is more complex than that of cross ventilation (Cui et al., 2016). The effective depth in a single-sided natural ventilation, can be considered as the distance of fresh air flowing from the window to the position where the room air prevails similarly to the flow to an air outlet (Gan, 2000).

There are two methods for characterizing the effective depth of fresh air. On the one hand, the value can be determined through the velocity distribution. On the other hand, it can be evaluated by the local mean age of air. In 1992, Walker and White (1992) reported their tracer gas experiments to determine local mean age of air at different locations in a single-sided ventilation room. In 1996, White and Walker (1996) found that the wind direction and buoyancy forces have some influences on distribution of local ventilation rates in their measurements about single-sided ventilation room. In 2000, Gan (2000) investigated how the air flow rate and 
effective depth are affected by the window location and internal heat gains by a numerical simulation. However, these researchers considered only the single-sided ventilation caused by the thermal force. For the single-sided ventilation driven by wind pressure, the problem of uneven distribution of fresh air, or the problem regarding the penetration depth of fresh air not able to cover the depth of the room would also exist, thus further analysis is required.

\subsection{Aim of the Work}

This paper aims to analyze the ventilation efficiency and effective ventilation flow rates of single-sided wind-driven natural ventilation buildings by numerical simulation. The numerical method is described and verified by existing cases. Afterward, effects of various influencing parameters, such as wind speed, opening location, opening area and aspect ratio of windward wall on effective ventilation flow rate, mixing coefficient and penetration depth of fresh air were investigated by numerical simulation. A constant value of mixing coefficient was established based on the existing models for ventilation rate evaluation.

It is well noted that the ventilation efficiency (mixing coefficient) as evaluated in this study is different from the traditional concept in mechanical ventilation. It is not the effective ventilation rate, but the ratio of effective ventilation rate to opening ventilation rate.

\section{CFD METHOD AND VALIDATION}

Theoretical analysis, numerical simulation and experiments are three important methods in the field of natural ventilation (Wang et al., 2018). The complexity of airflow in single-sided ventilation due to wind pressure poses a limitation on the method of theoretical analysis. Moreover, field experiments to determine the air velocity through windows are difficult to conduct (Wang and Chen, 2012). Therefore, many researchers use numerical simulation as a major method to analyze single-sided natural ventilation by adopting a Reynolds Averaged Navier-Stoke (RANS) or large eddy simulation (LES) turbulent model (Visagavel and Srinivasan, 2009; Ai and Mak, 2014; Wang et al., 2018; Arinami et al., 2019).

In 2011, Bu and Kato (2011) conducted both wind tunnel tests and numerical calculations for the same scale model, in order to analyze the natural ventilation of a basement. Their findings showed that the LES model can produce accurate results than by wind tunnel tests. However, RANS model is suitable to some degree, because of the relatively low cost of computation. Ai et al. (2014) and Gao et al. (2008) also concluded that the RNG k- $\varepsilon$ model can predict well for flow fields coupling of indoor and outdoor environment. Thus, the RNG k- $\varepsilon$ model was used in this study.

Moreover, there are two predictive methods for calculating ventilation rate of single-sided ventilation in numerical simulation. The effective ventilation rate can be obtained by the tracer gas decay method, and the air change rate through an opening can be determined by the integration method. The latter can be calculated by Eq. (1) (Ai and Mak, 2014).

$$
Q_{m}=\frac{\frac{1}{2} \sum_{i=1}^{l}\left(\sum_{m=1}^{M} \sum_{n=1}^{N}\left|U_{m, n}\right| \Delta y_{m} \Delta z_{n}\right) \Delta t^{i}}{\sum_{i=1}^{l} \Delta t^{i}}
$$

where $Q_{m}$ is the average value of the instantaneous ventilation volumes over time of $\sum_{i=1}^{1} \Delta t^{i}$. For each time step $\Delta t$, the instantaneous ventilation rate can be calculated by the product of velocity and opening area of tiny space. $\Delta y_{m} \Delta z_{n}$ is the area of each tiny cell on the opening face. $U_{m, n}$ is the velocities of the tiny cell. For steady numerical simulation, only the mean ventilation rate through an opening can be determined by Eq. (2) (Ai and Mak, 2014).

$Q=\frac{1}{2} \sum_{m=1}^{M} \sum_{n=1}^{N}\left|U_{m, n}\right| \Delta y_{m} \Delta z_{n}$ 
The effective ventilation rate can be calculated by the tracer gas multi-points decay method in transient simulation as given by Eq. (3) (Cui et al., 2015).

$$
Q^{*}=\frac{\left(\sum_{j=1}^{n} t_{j}\right) \sum_{j=1}^{n} \ln \left[C\left(t_{j}\right)-C_{b g}\right]-n \cdot\left(\sum_{j=1}^{n} t_{j}\right) \cdot \ln \left[C\left(t_{j}\right)-C_{b g}\right]}{n \sum_{j=1}^{n} t_{j}^{2}-\left(\sum_{j=1}^{n} t_{j}\right)^{2}} \cdot v_{\text {room }}
$$

where $V_{\text {room }}$ is building volume; $n$ is the total number of measured or calculated elapsed time points. $t_{j}$ is the $j$-th elapsed time from the decay process starting; $C\left(t_{j}\right)$ the calculated gas concentration at time $\left(t_{j}\right) ; C_{b g}$ the background tracer gas concentration.

The dimensionless results, $N Q$ and $N Q^{*}$, can be obtained based on the reference wind speed $U_{\text {ref }}$ and window opening area $A$ as given by Eqs. (4) and (5):

$$
\begin{aligned}
& N Q=\frac{Q}{U_{\text {ref }} A} \\
& N Q^{*}=\frac{Q^{*}}{U_{\text {ref }} A}
\end{aligned}
$$

In warren's model, the dimensionless ventilation rate is considered as a constant. Therefore, the mixing coefficient can be calculated by Eq. (6):

$f=\frac{Q^{*}}{Q}$

\subsection{Computational Geometry and Domain}

In order to analyze the general rules of mixing coefficient and represent the influence of indoor and outdoor flow on single-sided natural ventilation accurately, a geometrical model was established as shown in Fig. 1. The model is similar to other models (Jiang et al., 2003; Visagavel and Srinivasan, 2009; Wang and Chen, 2012; Wang et al., 2018).

The exterior dimensions of the building model were $L \times W \times H$. There was an opening in the windward wall with the size of $I \times h$. According to Tominaga et al. (2008), the sides and top boundaries of the external computational domain were set as $5 \mathrm{H}$ away from the corresponding external wall of the internal building, while the outflow and inlet boundaries were set as $15 \mathrm{H}$ and $5 \mathrm{H}$ away from the corresponding wall, respectively. The size of the entire external computational domain was $(\mathrm{L}+2 \mathrm{OH}) \times(\mathrm{W}+10 \mathrm{H}) \times(6 \mathrm{H})$, as shown in Fig. 2, with the blockage rate less than 3 percent. The whole computing domain was divided by hexahedral grid, with a minimum mesh size close to $0.015 \mathrm{H}$, as shown in Fig. 3. Grid systems of $1.04 \times 10^{6}, 2.88 \times 10^{6}, 5.48 \times 10^{6}$ were tested. Finally, the $2.88 \times 10^{6}$ grids were adopted for almost all cases as indicated below. Analysis of the ventilation efficiency as a further increase in mesh density did not produce obvious changes in the numerical solutions.

\subsection{Boundary Conditions and Initials Conditions}

The inlet velocity $U$ (horizontal velocity) is defined by Eq. (7), turbulent kinetic energy $k$ and turbulent dissipation rate $\varepsilon$ are defined by Eqs. (7) and (8) respectively, and these were inputted to the CFD software as velocity flow boundary condition (Richards and Norris, 1993):

$U=\frac{V^{*}}{K} \ln \left(\frac{z+z_{r o}}{z_{r o}}\right)$

$k=\frac{v^{* 2}}{\sqrt{c_{\mu}}}$ 


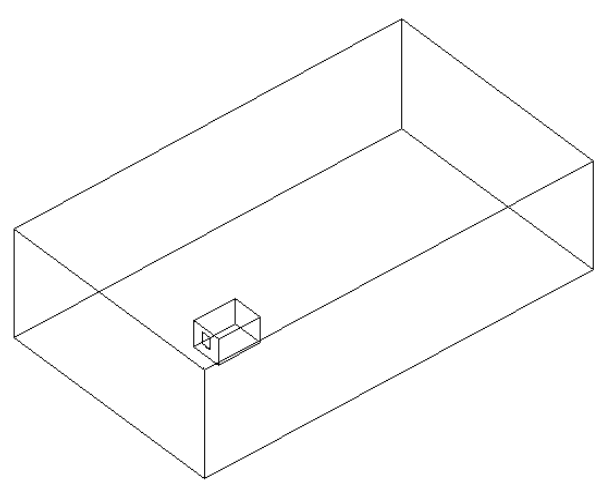

Fig. 1. The building model.

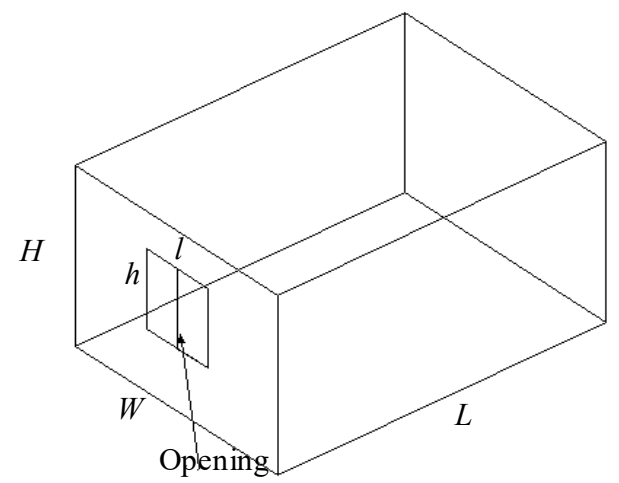

Fig. 2. The computational zone.

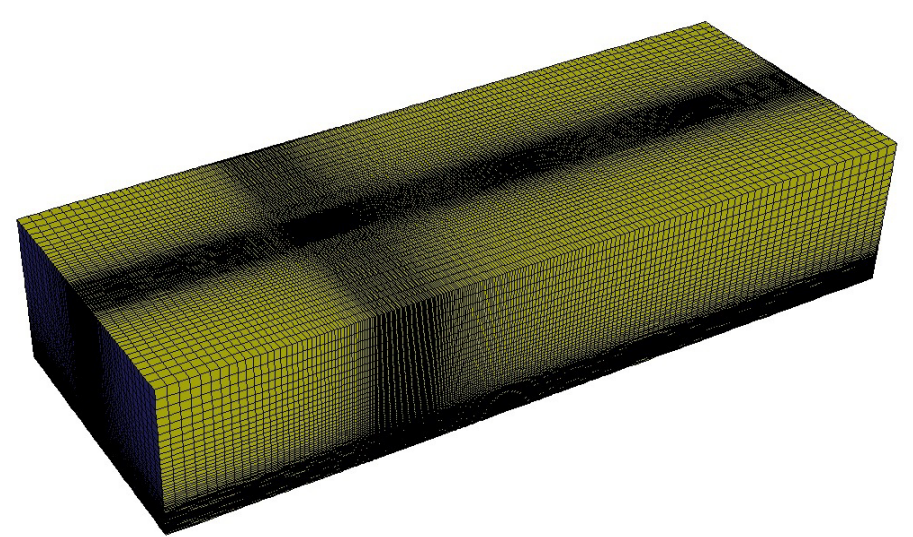

Fig. 3. Computational grid of the zone.

$\varepsilon=\frac{v^{* 3}}{K\left(z+z_{r o}\right)}$

where $z_{r 0}$ is the roughness length (equals to $0.01 \mathrm{~m}$ for most cases); $z$ is the height; $K$ is the Karman constant, which equals to $0.4 ; v^{*}$ is friction velocity of the atmospheric boundary layer, which is calculated by Eq. (10):

$$
v^{*}=\frac{K U_{r e f}}{\ln \left(\frac{10+z_{r o}}{z_{r o}}\right)}
$$


In the above equation, $U_{\text {ref }}$ is a given velocity at a reference height of $10 \mathrm{~m}$.

The outlet boundary condition of the computing zone was set as outflow, the lateral and top faces were set as planes of symmetry, and the other surfaces were all set as no-slip wall.

In transient simulation, the incoming flow and the flow around the building were set as a mixture of gases in initial conditions, with 0.9996 air and $0.0004 \mathrm{CO}_{2}$. The initial background concentration of $\mathrm{CO}_{2}$ in the building was set as 0.002 .

\subsection{Solver Settings}

In the simulation, it was solved by using the solution algorithm of segregated solver. The second order upwind scheme was used for the discretization of momentum, turbulent kinetic energy and turbulent dissipation rate. Pressure and velocity were coupled using the SIMPLE algorithm. Solution was considered converged when all residuals decrease to $1.0 \mathrm{e}-04$. When first convergence was reached, $Y$ plus adaption was performed. Then the case was simulated again. Finally, Y plus values range from 30 to 400 .

To reduce the consumption of time, the steady-state RNG k- $\varepsilon$ model was firstly selected, and then the result was taken as the initial value of RNG transient simulation. The calculation time was set as $3000 \mathrm{~s}$, the time step was $0.1 \mathrm{~s}$ according to the reference velocity and cell characteristic (Caciolo et al., 2012; Menter, 2012; Tzanakis, 2014; Fluent, 2016), and the maximum number of iterations of each time step was 10.

The ventilation rate through the window opening was obtained by using the velocity data of the steady-state simulation according to Eq. (2). The effective rate was obtained by using the concentration data of unsteady simulation according to Eq. (3).

\subsection{Validation of CFD Method}

In 2003, Jang conducted a wind tunnel experiment to study the principle of natural ventilation under wind pressure and compared the experimental data with the numerical simulation results. (Jiang et al., 2003). The study focused on small ( 0.25 cubic) building model with a window opening size $0.084 \mathrm{~m} \times 0.125 \mathrm{~m}$ (length $\times$ height), as shown in Fig. 4 . There is a workspace with area of $2.0 \mathrm{~m} \times 2.0 \mathrm{~m}$ and height $1.0 \mathrm{~m}$, which is in the wind tunnel. The velocity measurements were conducted on a grid plane at the centre of the building. The case with a windward opening was simulated by the LES model in Jiang's study, which was evaluated by the RANS model in the paper.

In order to verify the CFD method used in this paper, Jiang's case was chosen for the numerical simulation. Similar but different from the description of the part CFD method and validation, downstream length was set as $8 \mathrm{H}$; upstream length was $4 \mathrm{H}$; lateral length was $4 \mathrm{H}$ on both sides of the building in the computational zone. The Reynolds number was 140,000, which was calculated by the characteristic velocity at the building height in the inlet boundary. The mesh system of $3.02 \times 10^{6}$ grids was selected by grid verification.

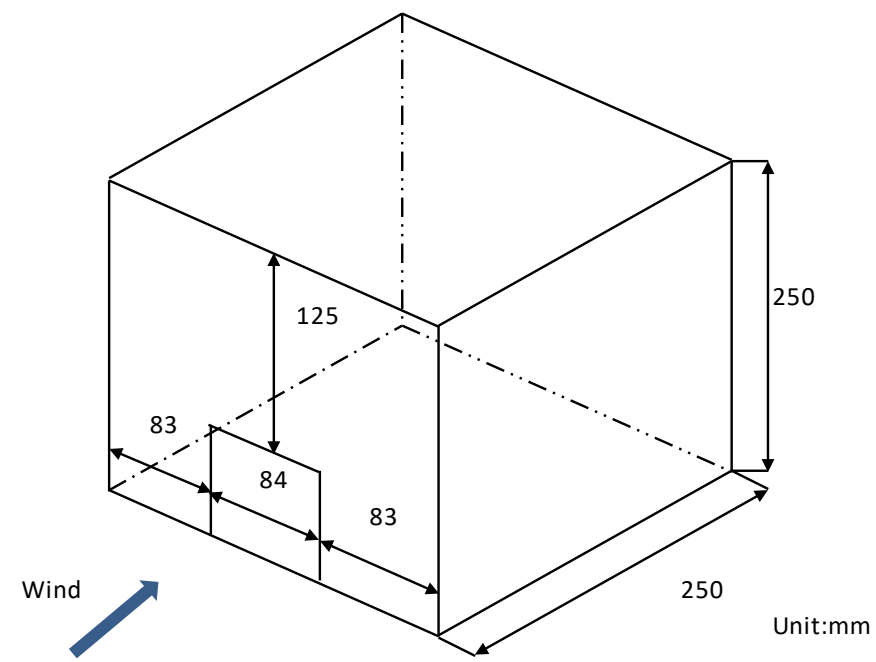

Fig. 4. A schematic view of the building model (Tzanakis and Anthanasios, 2014). 
The average instantaneous ventilation rate, $0.0027 \mathrm{~m}^{3} \mathrm{~s}^{-1}$, over a time period of $2.5 \mathrm{~s}$ was calculated by the LES model in Yang's study, according to Eq. (1). If the case was numerically calculated by the RANS model, the average instantaneous ventilation rate would be equal to $0.0022 \mathrm{~m}^{3} \mathrm{~s}^{-1}$. The result would be almost the same as the mean ventilation rate according to Eq. (2). Therefore, $Q=Q_{m}$ in the RANS simulation because of the average characteristics of the model. The difference between the LES model and the RANS model was small and then the latter one would be chosen in all the other cases considering the time consumption.

Fig. 5 shows the velocity distribution along centreline height of the stream wise section. The numerical results are shown in good agreement with the experimental data, and the relative error is less than $20 \%$ in most regions. Therefore, the CFD method adopted in the paper was validated for numerical simulation of the natural ventilation.

Fig. 6 illustrates the velocity vectors, showing the lateral velocity at a height of $0.08 \mathrm{~m}$ in a horizontal plane of the building. There are at least four vortices that occur on this surface. Two of them was near the entrance, which is a reason for the difference in the opening flow rate and effective ventilation flow rate.

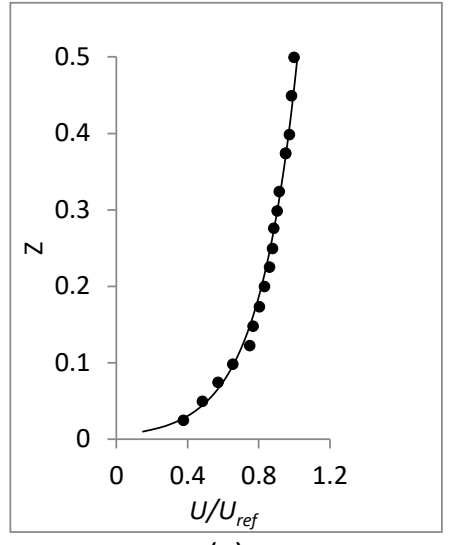

(a)

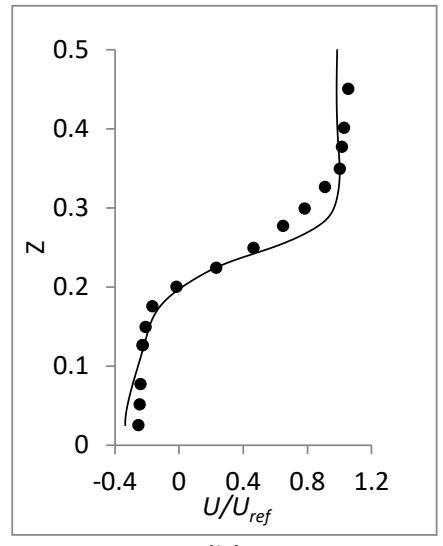

(b)

Fig. 5. The velocity distribution along stream wise centerline. Black dots: experiment; solid line: RANS model. (a) The section of $3 \mathrm{H}$ in front of the building and (b) The section of $1 / 2 \mathrm{H}$ behind the building

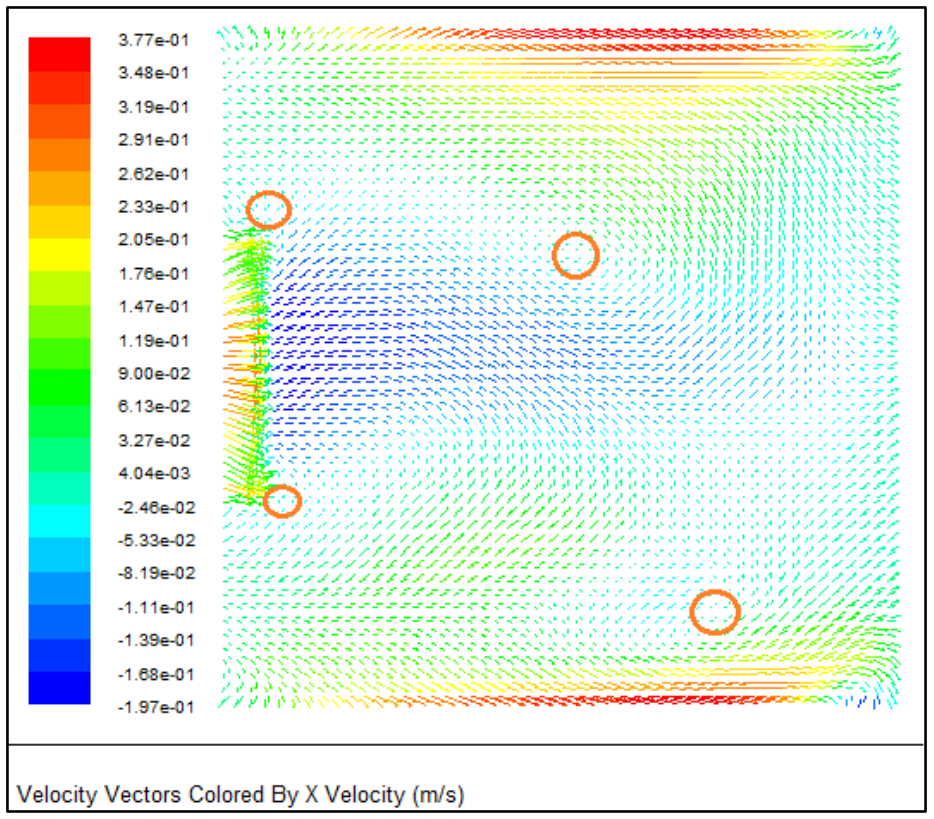

Fig. 6. The lateral velocity distribution of a horizontal plane in the cubic. 


\section{ANALYSIS OF VENTILATION EFFICIENCY}

In single-sided ventilation driven by wind pressure with one opening, the intake and the outlet are on the same plane. The wind speed at the high position is larger than low level for incoming flow. The fresh air flows into the room from the upper part of the opening, and then is squeezed out from the lower part. It can be considered that the ventilation rate is related to the wind pressure difference on the opening surface. The larger the air pressure difference, the better the ventilation effect. Therefore, it can be concluded that the performance of effective ventilation is related to the wind speed, opening area and room volume, etc. However, the law of the mixing coefficient cannot be inferred.

In this part, 23 cases were calculated and analyzed by numerical simulation in the following part. The relationships between mixing coefficients and influencing parameters were analyzed. Furthermore, the penetration depth of fresh air of different cases was also discussed by monitoring the variation of average absolute velocity in five surfaces, as shown in Fig. 7 . Each surface keeps one metre away from another along $X$ direction.

\subsection{Wind Speed}

The exterior dimensions of this building model were $6 \times 4 \times 3 \mathrm{~m}(L \times W \times H)$. One opening with the size of $1 \times 1 \mathrm{~m}(I \times h)$ was located in the centre of the windward face. Five cases with different wind speeds, are as shown in Figs. 8 and 9, were calculated by numerical simulation. Other settings are the same as above.

Fig. 8 compares the ventilation rate through opening $Q$ and effective ventilation rate $Q^{*}$ of all five cases. It shows that all ventilation rates rise linearly with an increase in wind speed, and the opening ventilation rate is always larger than the effective rate. Many models for calculating ventilation rate demonstrated a linear relationship between the ventilation rate and the wind speed (Warren and Parkins, 1977; Wang and Chen, 2012). This linear relationship can be seen in Fig. 8, which illustrates that both dimensionless air flow rates were kept constant with different wind speed.

Fig. 9 provides a summary of the mixing coefficients of these five cases, which are shown to decline with an increase in the wind speed. Therefore, the increase in the wind speed at the inlet boundary is beneficial to the air exchange, but the proportion of the air flow rate through window opening would contribute to the effective ventilation decreases. The exponential relation of mixing coefficient with wind speed, as given by Eq. (11), can be obtained from Fig. 8.

$f U_{\text {ref }}^{0.383}=0.56\left(R^{2}=0.99\right)$

The average absolute velocity distribution on five vertical sections set along the depth of the room is shown in Fig. 10.

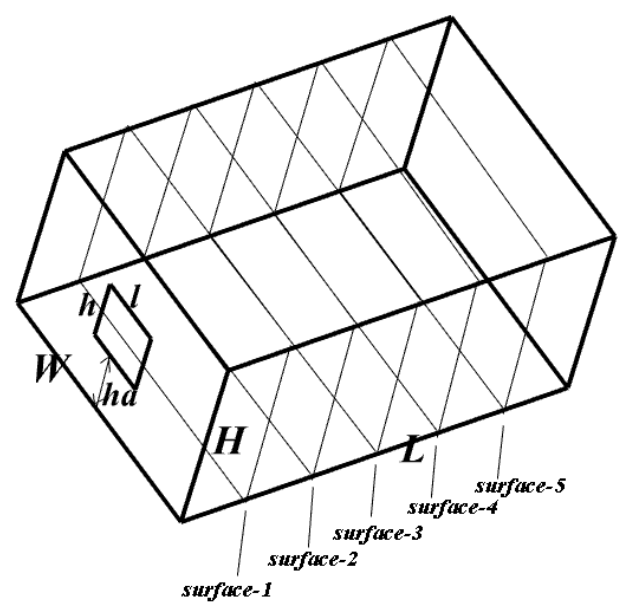

Fig. 7. Monitored surface in the physical model. 


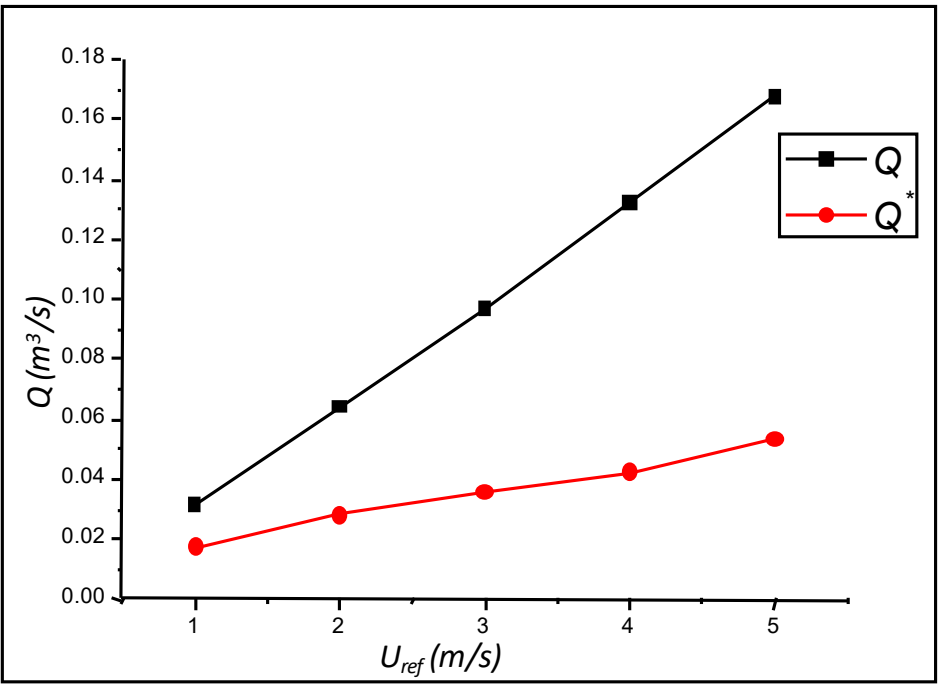

Fig. 8. Variation of ventilation rate changing with wind speed.

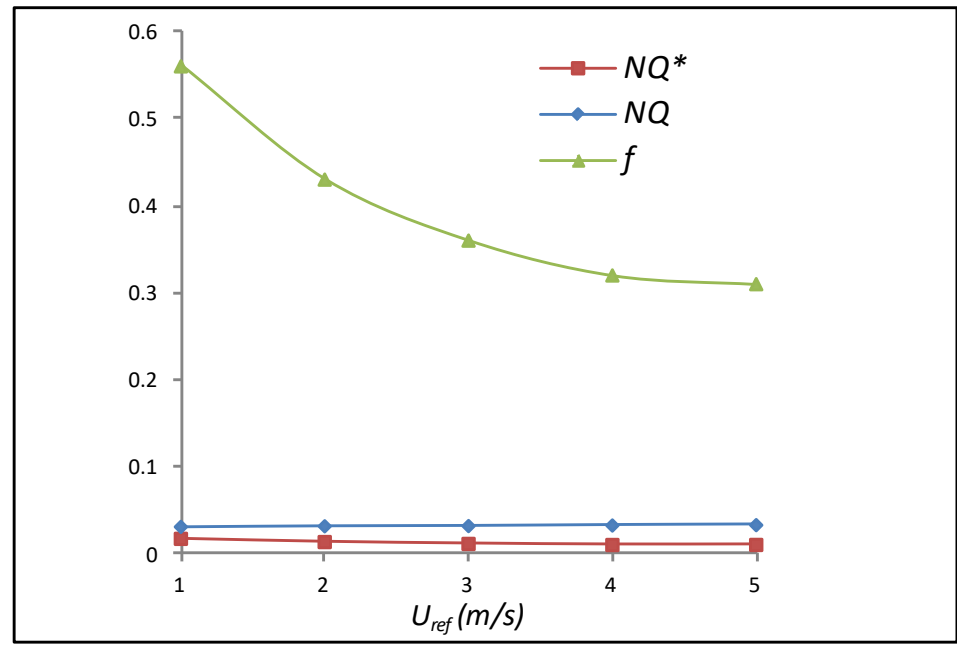

Fig. 9. Variation of mixing coefficient changing with wind speed.

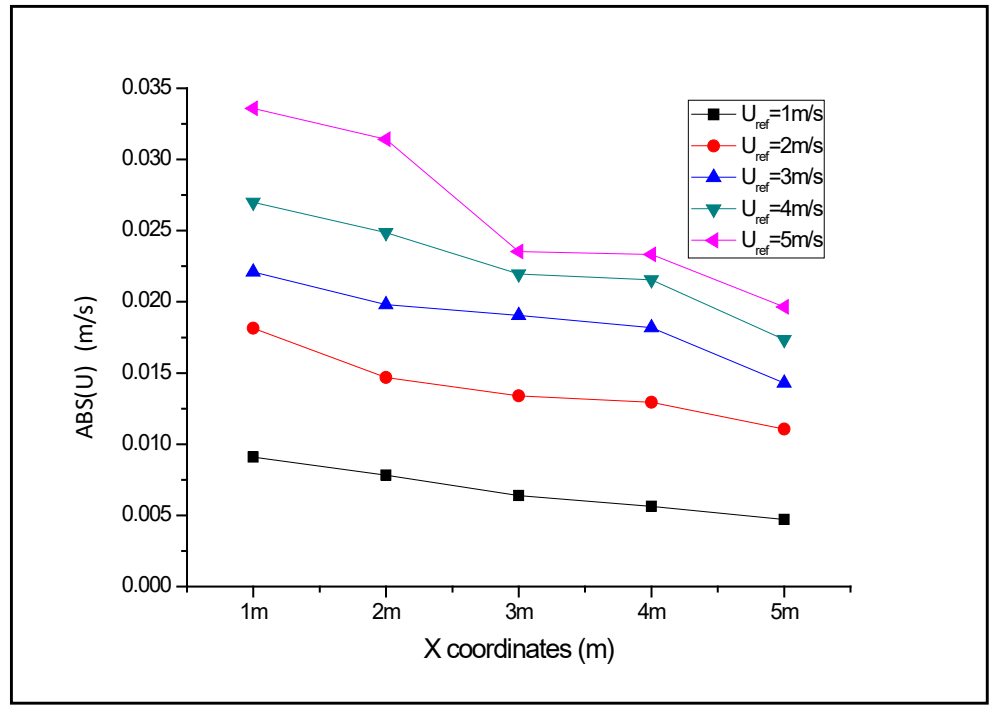

Fig. 10. Variation of average absolute velocity changing with different monitored surface. 
As can be seen from the above figures, due to the increase in the reference wind speed at the inlet boundary, the average absolute velocity of each monitored surface in the room is also increased gradually. In addition, the higher the reference wind speed would lead to a more obvious change in the average absolute velocity along the depth direction of the room, although, the change is slower. Due to the characteristic of the flow field in a single-sided ventilated room, the maximum depth that fresh air can actually penetrate into the room is difficult to predict. However, the greater the reference wind speed at the inlet flow boundary would lead to a greater increase in the average absolute velocity at the corresponding vertical interface, and therefore, the stronger the ability of the fresh air to reach the deep part of the room.

\subsection{Opening Location}

The influence of the position of the window opening on the effective ventilation of the room was analyzed. Five cases with various window openings in different vertical position were numerically calculated, with the same opening area and the same horizontal position. The vertical distances between the lower edge of the opening and the room floor were set as $0.2 \mathrm{~m}, 0.6 \mathrm{~m}, 1 \mathrm{~m}, 1.4 \mathrm{~m}$ and $1.8 \mathrm{~m}$ respectively.

According to the simulation results, the effective ventilation rate and opening air flow rate with different opening locations are shown in Fig. 11. The dimensionless ventilation rates and the mixing coefficients are summarized in Fig. 12.

As seen from Fig. 11 that both ventilation rates reach the minimum when the window opening is located at the centre of the windward face (the distance $h_{a}$ equal to 1 ). Along the vertical direction, the farther away from the centre of the windward face, the greater the ventilation rate would be. The possible reason is due to the effect of wind direction. When the direction of wind is directly perpendicular to the opening, the pulsating ventilation would be initiated, and the RANS model would be insufficient to describe this effect. On the contrary, the convection is the main influencing factor when the window opening is obliquely oriented to the approaching wind, as is shown by Ai's study (Ai and Mak, 2014).

However, as seen from Fig. 12 that the maximum value of mixing coefficient, 0.44 , appears at the position when the window opening is located at the positive centre (the distance $h_{a}$ equal to 1). Therefore, with the same opening size, the farther the opening is from the centre along the vertical direction, the more beneficial would be for the indoor effective ventilation, but only some of the proportion of the air change rate through opening would contribute to the effective ventilation.

The average absolute velocity distribution on the monitored surface along the depth direction of the room is shown in Fig. 13.

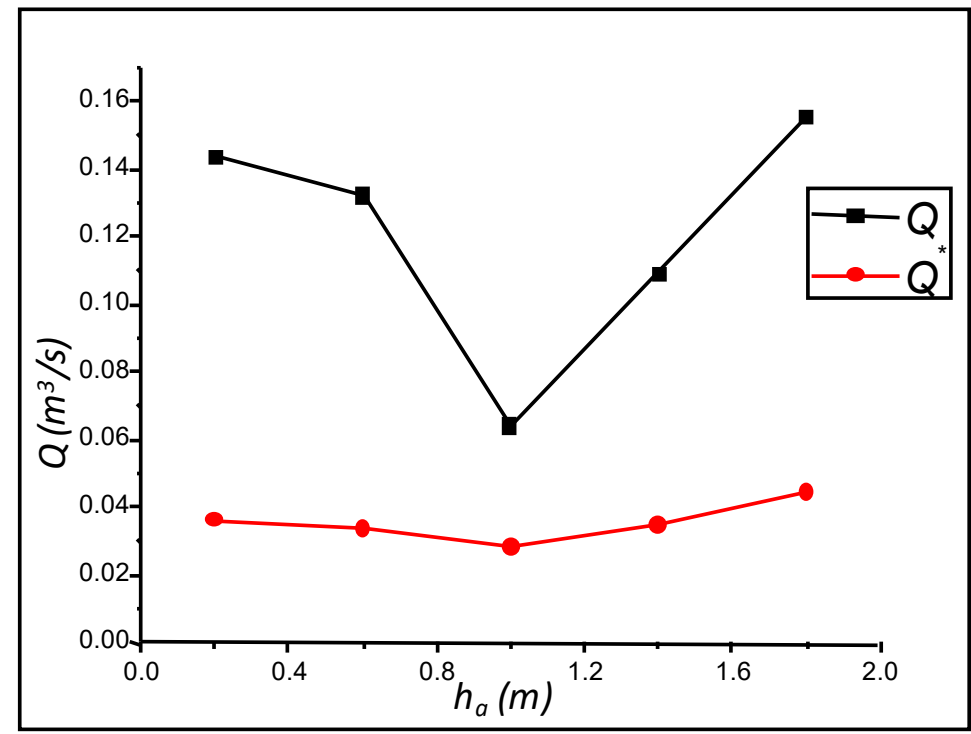

Fig. 11. Relationship between the ventilation rates and the opening location. 


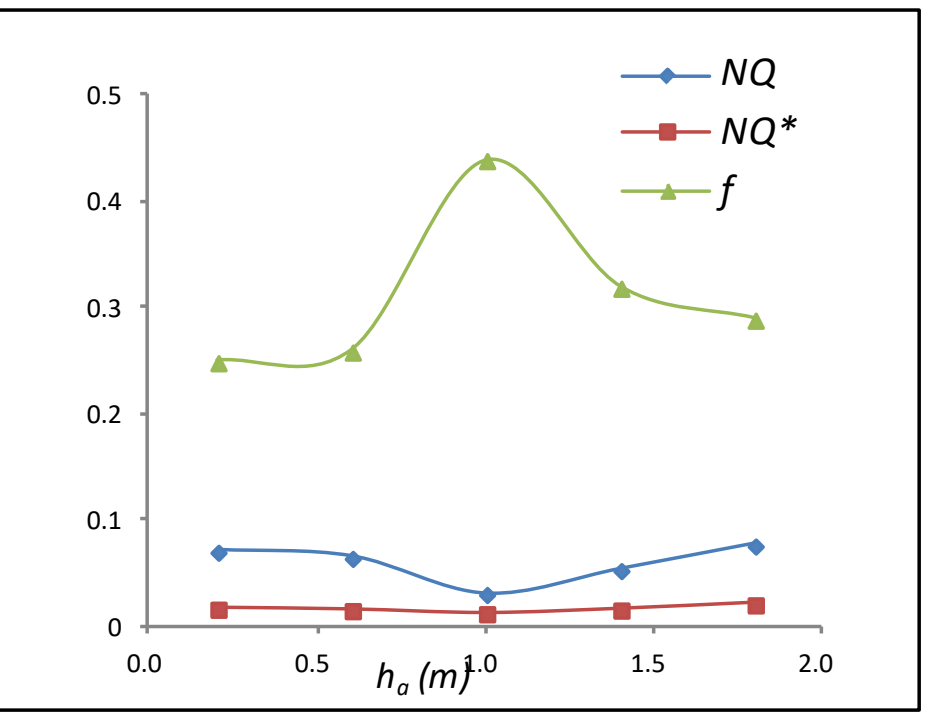

Fig. 12. Relationship between the mixing coefficient and the opening location.

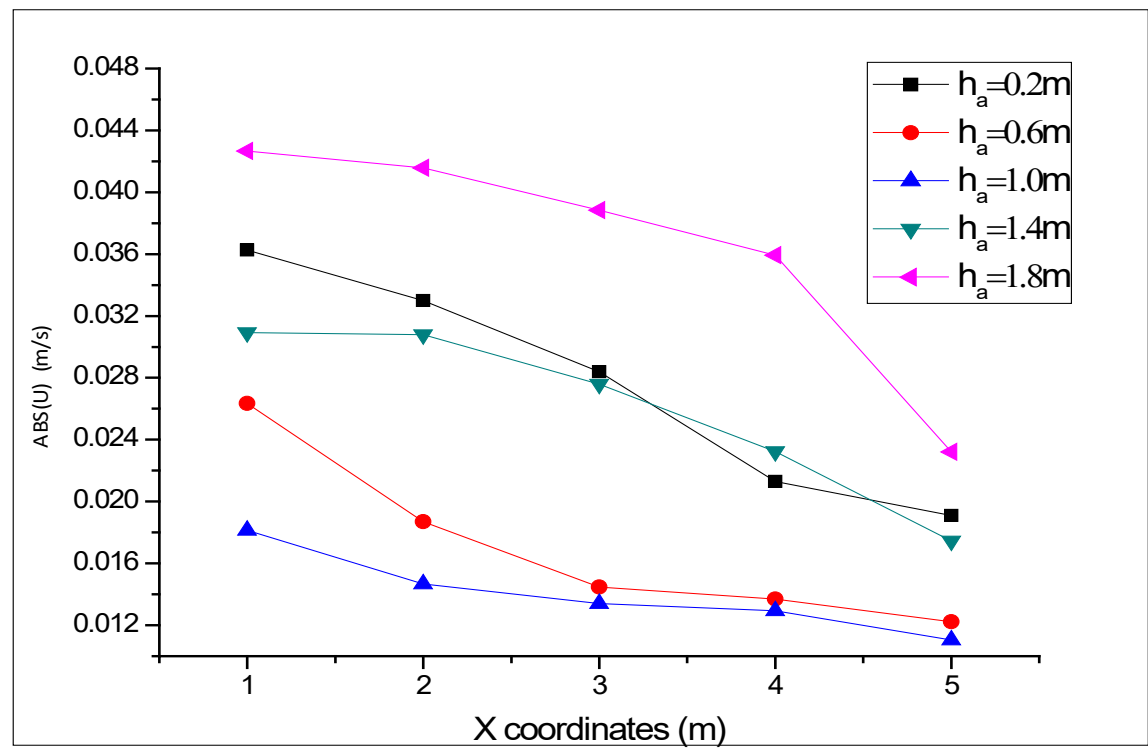

Fig. 13. Average absolute velocity distributions at monitored surface along the depth of the room.

From Fig. 13, the relationship between the average absolute velocity of each monitored surface and the opening location is consistent with the ventilation rate and the opening location, which is shown in Figs. 11 and 12. When the opening is located at the centre of the windward face, the average absolute velocity of each vertical section in the room is the minimum. When the opening is located at the top of the windward face, the average absolute velocity of each vertical section in the room would be the highest. According to this rule, the farther the opening is from the vertical distance to the centre of the windward face, the stronger the ability of the fresh air would be to reach deep into the room.

\subsection{Opening Area}

With the same building model but different opening area, eight cases were numerically simulated and compared, as shown in Table 2 . The ventilation rate and the mixing coefficient are shown in Figs. 14 and 15 respectively. Here, the aperture ratio is the ratio of the opening area and windward wall area of the building. 
Table 2. Ventilation rates and mixing coefficient with different opening area.

\begin{tabular}{|c|c|c|c|c|c|c|c|}
\hline \multirow{2}{*}{ Case } & \multirow{2}{*}{$\begin{array}{l}\text { Aperture ratio } \\
(\%)\end{array}$} & \multicolumn{3}{|c|}{ Opening size } & \multirow{2}{*}{$\begin{array}{l}\text { Ventilation rate } \\
\text { through opening } \\
Q\left(\mathrm{~m}^{3} \mathrm{~s}^{-1}\right)\end{array}$} & \multirow{2}{*}{$\begin{array}{l}\text { Effective } \\
\text { ventilation rate } \\
Q^{*}\left(\mathrm{~m}^{3} \mathrm{~s}^{-1}\right)\end{array}$} & \multirow{2}{*}{$\begin{array}{l}\text { Mixing } \\
\text { coefficient } \\
f\end{array}$} \\
\hline & & $h(\mathrm{~m})$ & $I(\mathrm{~m})$ & $A\left(\mathrm{~m}^{2}\right)$ & & & \\
\hline 1 & 3.00 & 0.6 & 0.6 & 0.36 & 0.0214 & 0.0084 & 0.393 \\
\hline 2 & 5.00 & 0.6 & 1 & 0.6 & 0.0383 & 0.0156 & 0.407 \\
\hline 3 & 8.33 & 1 & 1 & 1 & 0.0652 & 0.0280 & 0.429 \\
\hline 4 & 11.67 & 1 & 1.4 & 1.4 & 0.0981 & 0.0518 & 0.528 \\
\hline 5 & 16.33 & 1.4 & 1.4 & 1.96 & 0.1714 & 0.0909 & 0.530 \\
\hline 6 & 16.67 & 1 & 2 & 2 & 0.1748 & 0.0852 & 0.487 \\
\hline 7 & 27.00 & 1.8 & 1.8 & 3.24 & 0.4257 & 0.2305 & 0.541 \\
\hline 8 & 33.33 & 2 & 2 & 4 & 0.6576 & 0.3623 & 0.551 \\
\hline
\end{tabular}

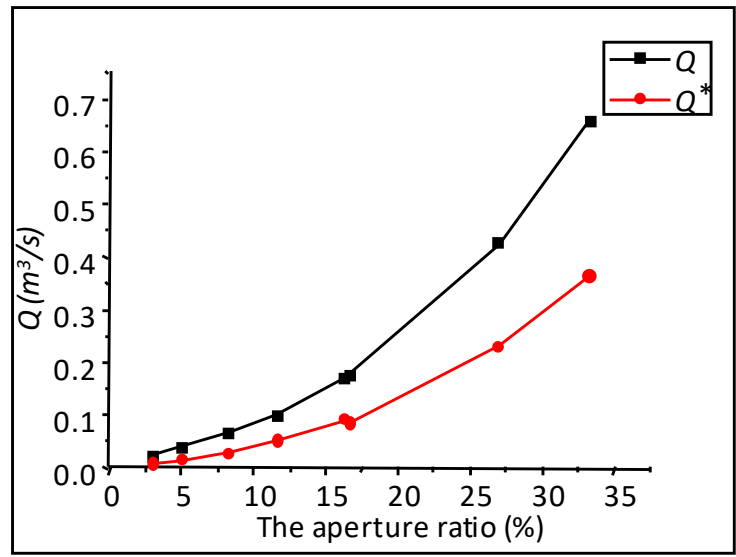

Fig. 14. Relationship between the ventilation rates and the aperture ratio.

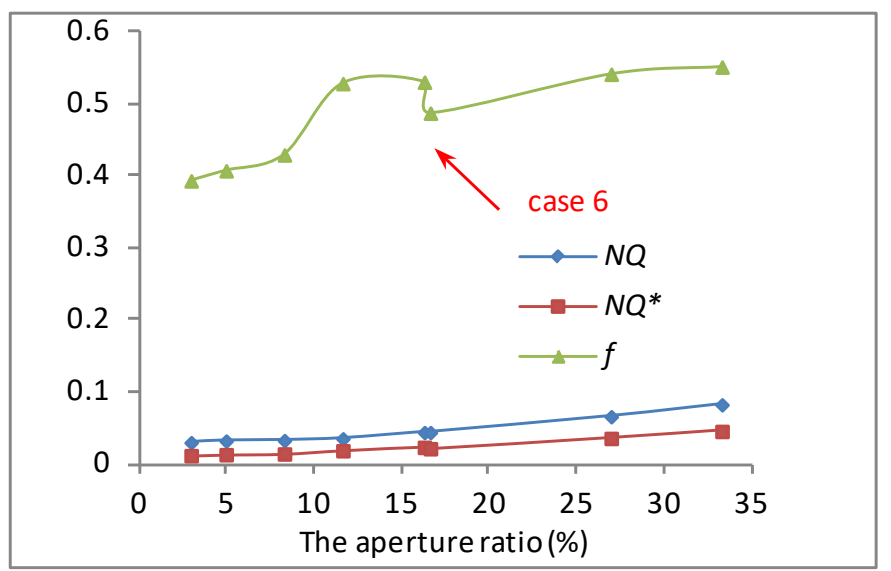

Fig. 15. Relationship between the mixing coefficient and the aperture ratio.

As is shown in Table 2 and Fig. 14, both ventilation rates increase with the increase of the window opening area (aperture ratio), and show a power exponential relationship. The opening rate for case 6 is larger than that in case 5. However, the effective ventilation rate of case 6 is slightly less than that in case 5 . This is also shown in Fig. 15. The most likely reason is that the effective ventilation rate is related to the aspect ratio of the opening and the opening area. With the same area, the effective ventilation is better for the case whose aspect ratio is closer to 1. Case 5 is exactly the special condition.

Fig. 15 describes the variation of mixing coefficient and dimensionless ventilation rate with aperture ratio. Both dimensionless ventilation rates were shown to increase slightly with the 


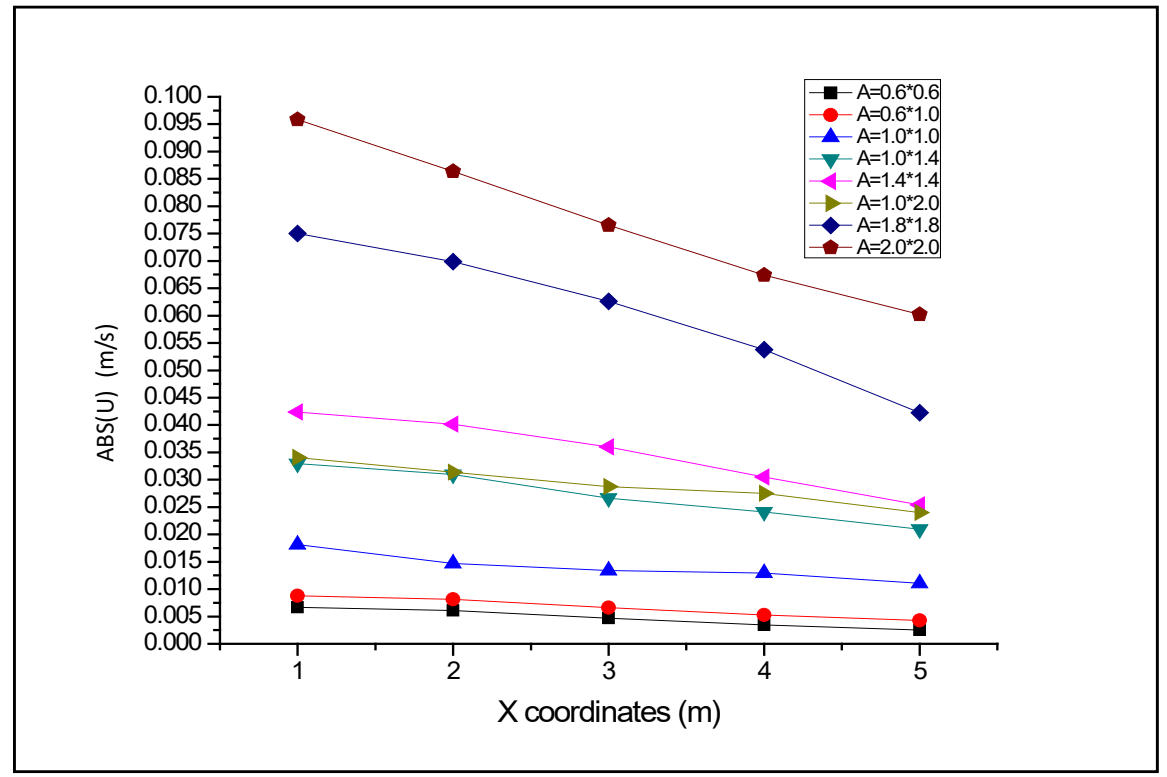

Fig. 16. Average absolute velocity distributions at vertical interfaces along the depth of the room.

aperture ratio. In general, both dimensionless ventilation rates can be considered irrelative to the opening area and keep the approximate constant value when the aperture ratio is smaller than $16 \%$. Considering the actual condition, the aperture ratio is often smaller than this threshold value. Therefore, this linear relationship is almost universal between ventilation rate and opening area.

Except in case 6, the mixing coefficient was shown to increase with the increase of aperture ratio. When the aperture ratio is roughly larger than $16 \%$, the increasing trend was shown to gradually slow down. Therefore, in general, the proportion of the air change rate through the opening that contribute to the effective ventilation would be increased with the increase of the window opening area.

Fig. 16 illustrates the average absolute velocity distribution at each monitored surface along the depth of the room. The average absolute air velocity of the vertical interfaces was shown to increase with the increase of the opening area. Therefore, the larger the opening area, the stronger would be the ability of the fresh air to reach deep into the room. When the opening area is the same and the ratio of the width to the height of the window opening would be closer to 1 , and the average absolute velocity of indoor vertical interfaces would be larger, leading to a better air exchange effect.

\subsection{Aspect Ratio of Windward Wall}

Five cases were numerically simulated and compared by varying the width of the room, as shown in Table 3, Figs. 17 and 18. The reference wind speed was set to $2 \mathrm{~m} \mathrm{~s}^{-1}$ in all cases.

As shown the Table 3, Figs. 17 and 18, the ventilation rates and dimensionless ventilation rates decline initially and then slowly increase with the increase of the width of room (which also

Table 3. The ventilation rates and mixing coefficient for different aspect ratio of windward wall.

\begin{tabular}{lllllll}
\hline Case & $\begin{array}{l}\text { Building size } \\
\mathrm{W} \times \mathrm{L} \times \mathrm{H}(\mathrm{m})\end{array}$ & $\begin{array}{l}\text { Opening size } \\
h \times l(\mathrm{~m})\end{array}$ & $\begin{array}{l}\text { Aperture rate } \\
(\%)\end{array}$ & $\begin{array}{l}\text { Average ventilation } \\
\text { volume } Q\left(\mathrm{~m}^{3} \mathrm{~s}^{-1}\right)\end{array}$ & $\begin{array}{l}\text { Effective ventilation } \\
\text { volume } Q^{*}\left(\mathrm{~m}^{3} \mathrm{~s}^{-1}\right)\end{array}$ & $\begin{array}{l}\text { Mixing } \\
\text { coefficient } \\
f\end{array}$ \\
\hline 1 & $2 \times 6 \times 3$ & $1 \times 1$ & 16.67 & 0.1877 & 0.0457 & 0.243 \\
2 & $3 \times 6 \times 3$ & $1 \times 1$ & 11.11 & 0.1140 & 0.0335 & 0.294 \\
3 & $4 \times 6 \times 3$ & $1 \times 1$ & 8.33 & 0.0652 & 0.0280 & 0.429 \\
4 & $5 \times 6 \times 3$ & $1 \times 1$ & 6.67 & 0.0773 & 0.0405 & 0.524 \\
5 & $6 \times 6 \times 3$ & $1 \times 1$ & 5.56 & 0.1097 & 0.0557 & 0.508 \\
\hline
\end{tabular}




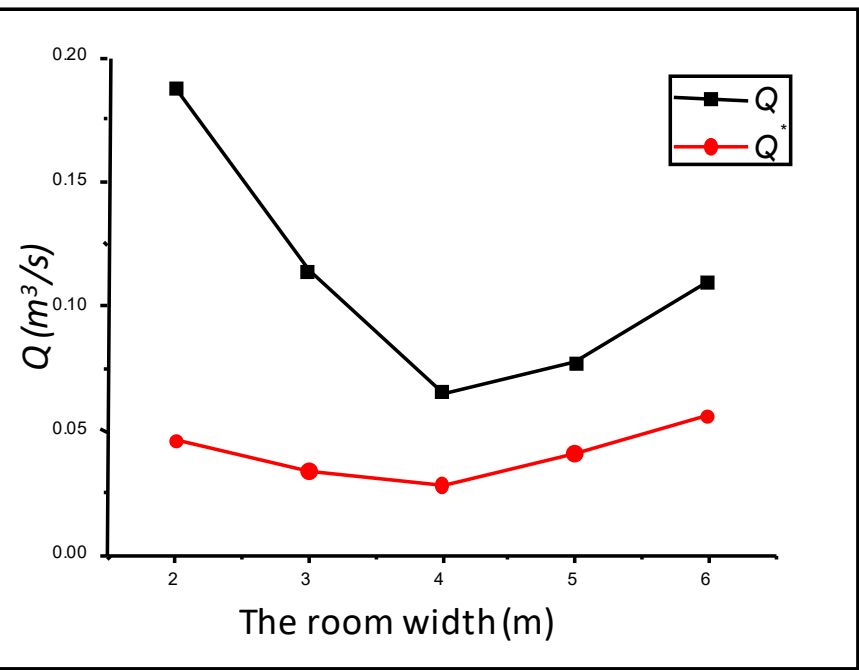

Fig. 17. Relationship between ventilation rates and room width.

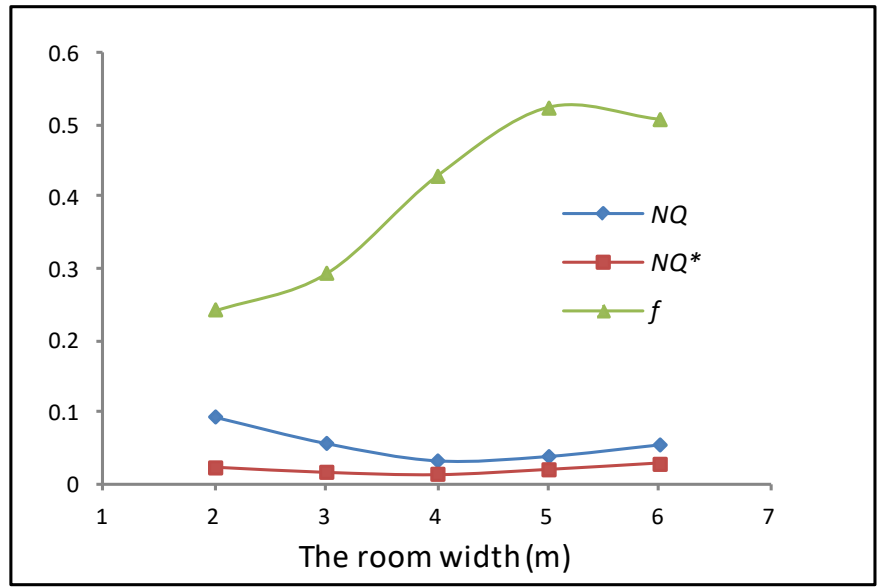

Fig. 18. Relationship between mixing coefficient and room width.

represents the increase of room volume). The minimum values of ventilation rates was established when the width of room was $4 \mathrm{~m}$ (case 3). Fig. 18 shows that the mixing coefficient would increase initially and then decline slowly with the increase of the width of room. The maximum value of mixing coefficient was established in case 4 with the aspect ratio of 5:3. However, the minimum ventilation rates occur for case 3 with the aspect ratio of 4:3.

When the window opening size was kept constant, the aperture ratio would be decrease with the increase of room width. As shown in Fig. 17, the ventilation rate would decline initially and then increase with the decrease of the aperture rate. This is inconsistent with the conclusion in the previous section. Therefore, when considering the influence of the aperture ratio on the ventilation rate, a consideration of two cases is necessary; i.e., the variation in the aperture ratio caused by the different windward wall area, and the variation in the aperture ratio caused by the different opening area.

\section{THE ESTIMATION OF MIXING COEFFICIENT}

As mentioned in the Introduction, the mixing coefficient is considered as a constant of $37 \%$ or $31.7 \%$ in previous studies (Cockroft and Robertson, 1976; Bu and Kato, 2016). In this study, the mixing coefficient was shown to vary with the variation of wind speed, opening location, opening area and room volume. Through summarizing all the results of the numerical simulation, the 
mixing coefficient was shown to vary from $25 \%$ to $55.1 \%$. However, a rough estimate value would still be needed to assess the ventilation efficiency generally when only the bulk ventilation rate through the window opening is known.

In earlier studies, some empirical formulas were put forward to estimate the ventilation rate of the single-sided ventilation, as Table 1 shows. In warren's study, the simple formula to solve the effective ventilation rate of the wind-driven natural ventilation $Q^{*}$ is as described by Eq. (12) (Warren and Parkins, 1977).

$Q^{*}=0.025 A U_{\text {ref }}$

where $A$ is the opening area and $U_{\text {ref }}$ is reference wind speed.

By comparing different correlation of natural ventilation with experiments, Caciolo et al. (2013) found that the Warren's model would produce the best results in the windward condition but overestimate in the leeward condition. The similar conclusion also had been got by Gough et al. (2020). Therefore, the Warren's model was chosen to calculate the accurate effective ventilation rate in this study. In addition, Wang and Chen (2012) proposed a model, as shown in Eq. (13) to predict the single-sided natural ventilation driven by wind pressure, which only refers to the opening air exchange.

$Q=\frac{C_{d} I \sqrt{C_{p}} \int_{z_{0}}^{h} \sqrt{z^{2 / 7}-z_{o}^{2 / 7}} d z}{z_{\text {ref }}^{1 / 7}} U_{\text {ref }}$

This equation is adopted here to calculate the ventilation rate through the window opening. Therefore, the mixing coefficient was calculated by Eq. (14):

$f=\frac{Q^{*}}{Q}=\frac{0.025 h}{C_{d} \sqrt{C_{p}}\left(\int_{z_{0}}^{h} \sqrt{z^{2 / 7}-z_{0}^{2 / 7}} d_{z}\right) / z_{r e f}^{1 / 7}}$

where $h$ and $/$ are the opening height and width, $C_{d}$ and $C_{p}$ are the discharge coefficient and the wind pressure coefficient respectively. $z_{0}$ is the position of the neutral plane. $z_{\text {ref }}$ is the reference height, which equals to $10 \mathrm{~m}$ in this paper. The neutral plane is the surface where the internal pressure equals to outer pressure.

The height of the neutral plane is obtained from Eq. (15) (Zhou et al., 2017):

$\int_{z_{0}}^{h} \sqrt{z^{2 / 7}-z_{0}^{2 / 7}} d_{z} \approx 0.209 \mathrm{~h}-0.031 \quad(h>0.2 \mathrm{~m})$

$\sqrt{C_{\mathrm{p}}}=0.7, C_{d}=0.6$ when the open plane is perpendicular to the direction of the wind flow (Larsen and Heiselberg, 2008).

Therefore, the mixing coefficient can be determined by Eq. (16):

$f=\frac{0.396 h}{h-0.148}(h>0.2 \mathrm{~m})$

The relationship between the mixing coefficient and the window opening height is depicted in Fig. 19, which shows that the mixing coefficient would decrease with the window opening height, and a constant would be maintained close to 0.45 when $h>0.5 \mathrm{~m}$. This is only a rough estimate value because the mixing coefficient is only related to the window opening height in this method. This conclusion can only be obtained when the wind pressure coefficients $\left(C_{p}\right)$ and the discharge coefficients $\left(C_{d}\right)$ are constant. Indeed, many factors could influence the wind pressure coefficients, like wind direction and building shape, etc. (Cóstola et al., 2009). The discharge coefficients could also be influenced by the wind pressure difference, the window opening area and so on (Heiselberg et al., 2001). Therefore, the mixing coefficient would vary with many parameters as discussed above. 


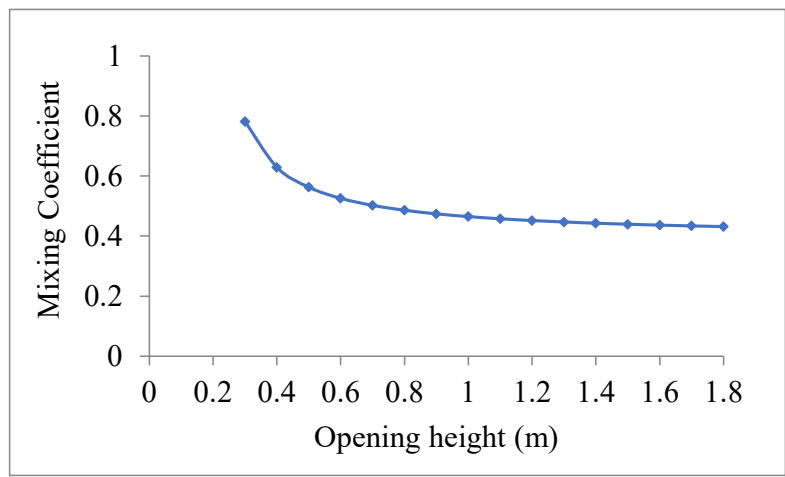

Fig. 19. Relationship between the mixing coefficient and opening height.

Table 4. The relative error of average mixing coefficients.

\begin{tabular}{llll}
\hline The influencing factors & The average value & The estimate value & The relative error \\
\hline Wind speed & 0.40 & 0.45 & 12.50 \\
Opening location & 0.50 & & 10.00 \\
Opening area & 0.48 & & 6.00 \\
Aspect ratio of windward wall & 0.40 & 12.50 \\
\hline
\end{tabular}

The numerical results and the estimated value of mixing coefficient can be compared here. For example, the maximum value of mixing coefficient is 0.44 based on different window opening location (as shown in Fig. 12), which is very close to rough estimate value 0.45 . When the opening area is considered, the relative difference between the estimated value (0.45) and numerical results of mixing coefficient would be smaller than $20 \%$, with the aperture ratio being in the range of $8 \%-27 \%$. The average value of mixing coefficients calculated by numerical simulation is listed in the Table 4. It can be seen that the relative error of average value comparing to estimated number is generally smaller than $15 \%$. Therefore, the estimated value is considered acceptable in the view of engineering.

\section{CONCLUSIONS}

In natural ventilation, effective flow rates are lower than the bulk airflow through the building's openings. The ventilation efficiency or mixing coefficient was discussed by a series of numerical simulation. The main conclusions of the paper are as follows:

(1) The penetration depth of fresh air would represent the effective ventilation capacity of the single-sided ventilation, which is the same as the effective ventilation rate. The higher the effective ventilation rate is, the deeper the penetration depth of fresh air would be in the room.

(2) The airflow rates through the window opening and the effective ventilation rate would all rise linearly with the incoming wind speed. However, the mixing coefficient would be decreased with an increase in the wind speed, the exponential relationship of them can be illustrated by $f U_{r e f}^{0.383}=0.56 \quad\left(R^{2}=0.99\right)$.

(3) With the same opening size, the farther the opening centre is from the centre of windward wall, the larger the ventilation rates. However, the mixing coefficient has a maximum value when the opening is located at the centre of windward wall.

(4) The airflow rates through the window opening and the effective ventilation rate would both be increased due to the window opening area. A linear relationship between the ventilation rates and the aperture ratio would be established in the cases in which the dimensionless ventilation rates is kept constant, and when the aperture ratio is smaller than $16 \%$. The mixing coefficient is also increased with the window opening area. Moreover, the effective ventilation is better in the case whose aspect ratio is closer to 1 , when the window opening areas are similar. 
(5) The ventilation rates and dimensionless ventilation rates would initially decline and then slowly increase with the increase in the width of room (or the increase in the room volume). The two ventilation rates would reach a minimum value when the aspect ratio of the windward wall is $4: 3$. The maximum mixing coefficient would be established when the aspect ratio is $5: 3$.

(6) In view of engineering, the correlation formula shows that the mixing coefficient would decline with the height of the window opening and 0.45 is considered as the estimation value. The estimate value can be used to assess the effective ventilation rate generally when only bulk ventilation rate through opening is known.

According to these results, the study can give some guidance for building design or performance evaluation on natural ventilation and provide some useful ideas as well as approach and methodology for the development of energy-efficient buildings. In special condition, such as the coronavirus epidemic, the effective ventilation rate and the mixing coefficient can help us to evaluate the infection risk of different buildings around hospital or shelters.

However, the numerical simulation in this study did not take into account the fluctuation of the incoming wind, and the RANS modelling cannot calculate the turbulence characteristics of the natural ventilation in detail in comparison with the LES modelling. Moreover, the object of the numerical simulation in this study is an isolate building with one opening. When an actual building with many rooms is considered, the variation in the ventilation efficiency would be likely be different. Then the problem of ventilation efficiency (mixing coefficient) would still need further investigation in future work.

\section{APPENDIX}

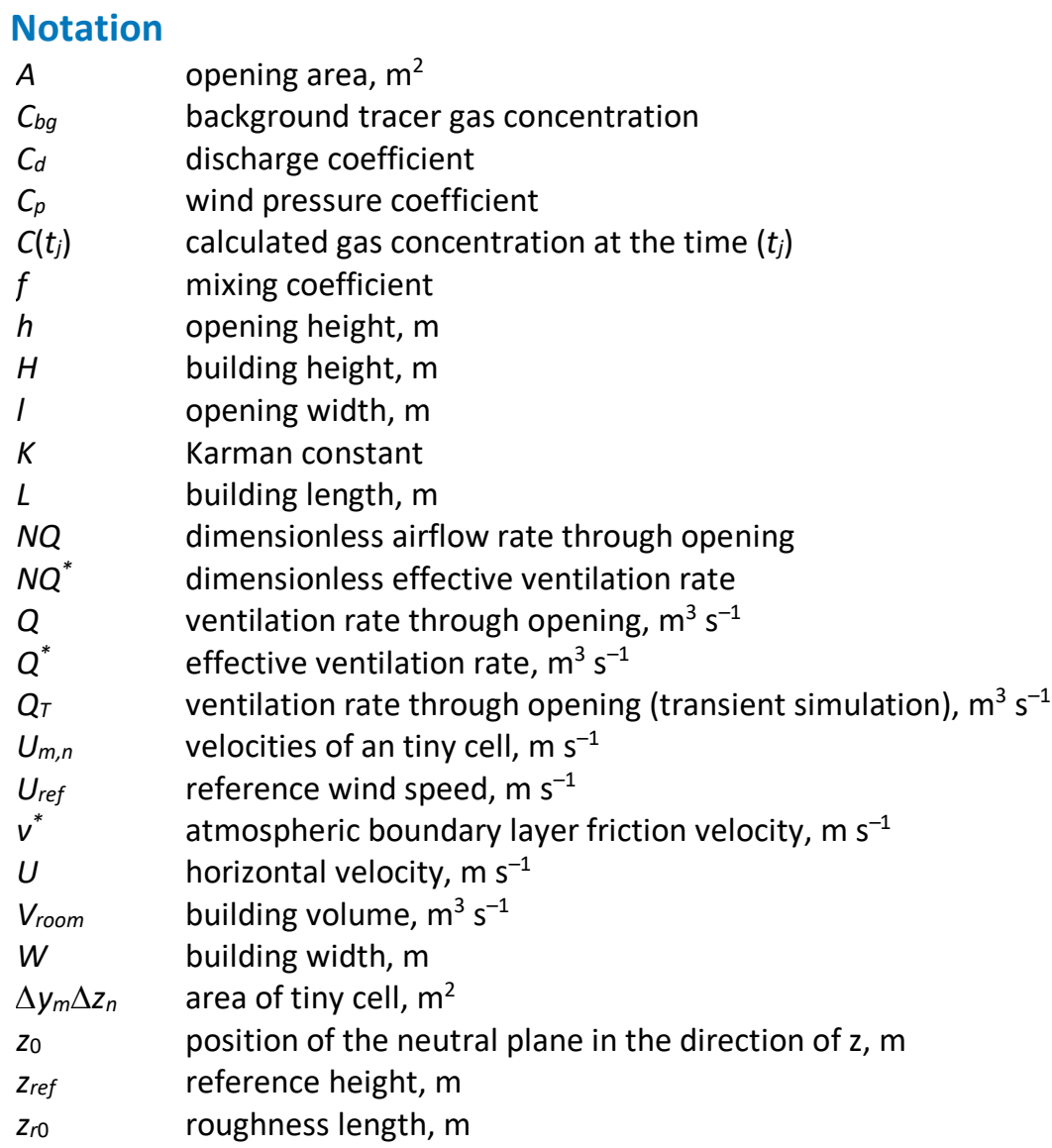

\section{Greek Symbols}

$k \quad$ Turbulent Kinetic Energy, $\mathrm{m}^{2} \mathrm{~s}^{-2}$

$\varepsilon \quad$ Turbulent Dissipation Rate, $\mathrm{m}^{2} \mathrm{~s}^{-3}$ 


\section{ACKNOWLEDGMENT}

This work was supported by the National Key Research and Development Program of China (2018YFC0704301, 2018YFD1100700).

\section{REFERENCES}

Abdullah, H.K., Alibaba, H.Z. (2020). Open-plan office design for improved natural ventilation and reduced mixed mode supplementary loads. Indoor Built Environ. https://doi.org/10.1177/142 $0326 \times 20953458$

Aflaki, A., Mahyuddin, N., Baharum, M.R. (2016). The influence of single-sided ventilation towards the indoor thermal performance of high-rise residential building: A field study. Energy Build. 126, 146-158. https://doi.org/10.1016/j.enbuild.2016.05.017

Aflaki, A., Mahyuddin, N., Mahmoud, Z.A.C., Baharum, M.R. (2015). A review on natural ventilation applications through building façade components and ventilation openings in tropical climates. Energy Build. 101, 153-162. https://doi.org/10.1016/j.enbuild.2015.04.033

Ai, Z.T., Mak, C.M. (2014). Modeling of coupled urban wind flow and indoor air flow on a highdensity near-wall mesh: Sensitivity analyses and case study for single-sided ventilation. Environ. Modell. Software 60, 57-68. https://doi.org/10.1016/j.envsoft.2014.06.010

Ai, Z.T., Mak, C.M. (2018). Wind-induced single-sided natural ventilation in buildings near a long street canyon: CFD evaluation of street configuration and envelope design. J. Wind Eng. Ind. Aerodyn. 172, 96-106. https://doi.org/10.1016/j.jweia.2017.10.024

Ai, Z.T., Mak, C.M., Niu, J.L. (2013). Numerical investigation of wind-induced airflow and interunit dispersion characteristics in multistory residential buildings. Indoor Air 23, 417-429. https:/doi.org/10.1111/ina.12041

Ai, Z.T., Mak, C.M., Niu, J.L., Li, Z.R., Zhou, Q. (2011). The Effect of balconies on ventilation performance of low-rise buildings. Indoor Built Environ. 20, 649-660. https://doi.org/10.1177/ $1420326 \times 11409457$

ANSYS Inc. (2016). Fluent Introduction 17.0, Module 10: Transient Flow Modeling.

Arinami, Y., Akabayashi, S., Tominaga, Y., Sakaguchi, J. (2019). Performance evaluation of singlesided natural ventilation for generic building using large-eddy simulations: Effect of guide vanes and adjacent obstacles. Build. Environ. 154, 68-80. https://doi.org/10.1016/j.buildenv. 2019.01.021

Bai, G., Gong, G., Yu, C.W.F., Zhen, O. (2015). A combined, large, multi-faceted bulbous façade glazed curtain with open atrium as a natural ventilation solution for an energy efficient sustainable office building in Southern China. Indoor Built Environ. 24, 813-832. https://doi.org/10.1177/1420326X15602048

$\mathrm{Bu}, \mathrm{Z}$., Kato, S. (2011). Wind-induced ventilation performances and airflow characteristics in an areaway-attached basement with a single-sided opening. Build. Environ. 46, 911-921. https://doi.org/10.1016/j.buildenv.2010.10.019

$\mathrm{Bu}$, Z., Kato, S. (2016). Investigation of ventilation effectiveness for wind-driven single-sided ventilated buildings located in an urban environment. Int. J. Vent. 10, 19-30. https://doi.org/ 10.1080/14733315.2011.11683932

Caciolo, M., Cui, S., Stabat, P., Marchio, D. (2013). Development of a new correlation for singlesided natural ventilation adapted to leeward conditions. Energy Build. 60, 372-382. https://doi.org/10.1016/j.enbuild.2013.01.024

Caciolo, M., Stabat, P., Marchio, D. (2011). Full scale experimental study of single-sided ventilation: Analysis of stack and wind effects. Energy Build. 43, 1765-1773. https://doi.org/1 0.1016/j.enbuild.2011.03.019

Caciolo, M., Stabat, P., Marchio, D. (2012). Numerical simulation of single-sided ventilation using RANS and LES and comparison with full-scale experiments. Build. Environ. 50, 202-213. https://doi.org/10.1016/j.buildenv.2011.10.017

CEN/TC156, EN 15242:2007 (2007). Ventilation for buildings - Calculation methods for the determination of air flow rates in buildings including infiltration. German Institute for Standardization. 
Cockroft, J.P., Robertson, P. (1976). Ventilation of an enclosure through a single opening. Build. Environ. 11, 29-35. https://doi.org/10.1016/0360-1323(76)90016-0

Cóstola, D., Blocken, B., Hensen, J.L.M. (2009). Overview of pressure coefficient data in building energy simulation and airflow network programs. Build. Environ. 44, 2027-2036. https://doi.org/10.1016/j.buildenv.2009.02.006

Cui, S., Cohen, M., Stabat, P., Marchio, D. (2015). CO2 tracer gas concentration decay method for measuring air change rate. Build. Environ. 84, 162-169. https://doi.org/10.1016/j.buildenv.20 14.11.007

Cui, S., Stabat, P., Marchio, D. (2016). Numerical simulation of wind-driven natural ventilation: Effects of loggia and facade porosity on air change rate. Build. Environ. 106, 131-142. https://doi.org/10.1016/j.buildenv.2016.03.021

da Graça, G.C. (2018). A technical note on simplified modeling of turbulent mixing in wind-driven single sided ventilation. Build. Environ. 131, 12-15. https://doi.org/10.1016/j. buildenv.2018.0 1.014

De Gids, W.F., Phaff, H. (1982). Ventilation rates and energy consumption due to open windows. Air Infilt. Rev. 4, 4-5.

Fung, Y.W., Lee, W.L. (2015). Identifying the most influential parameter affecting natural ventilation performance in high-rise high-density residential buildings. Indoor Built Environ. 24, 803-812. https://doi.org/10.1177/1420326X14536189

Gan, G. (2000). Effective depth of fresh air distribution in rooms with single-sided natural ventilation. Energy Build. 31, 65-73. https://doi.org/10.1016/S0378-7788(99)00006-7

Gao, N.P., Niu, J.L., Perino M., Heiselberg P. (2008). The airborne transmission of infection between flats in high-rise residential buildings: Tracer gas simulation. Build. Environ. 43, 18051817. https://doi.org/10.1016/j.buildenv.2007.10.023

Gough, H.L., Barlow, J.F., Luo, Z., King, M.F., Grimmond, C.S.B. (2020). Evaluating single-sided natural ventilation models against full-scale idealised measurements: Impact of wind direction and turbulence. Build. Environ. 170, 106556. https://doi.org/ 10.1016/j.buildenv.2019.106556

Haw, L.C., Saadatian, O., Sulaiman, M.Y., Mat, S., Sopian, K. (2012). Empirical study of a windinduced natural ventilation tower under hot and humid climatic conditions. Energy Build. 52, 28-38. https://doi.org/10.1016/j.enbuild.2012.05.016

Hayati, A., Mattsson, M., Sandberg, M. (2017). Single-sided ventilation through external doors: Measurements and model evaluation in five historical churches. Energy Build. 141, 114-124. https://doi.org/10.1016/j.enbuild.2017.02.034

Heiselberg, P., Svidt, K., Nielsen, P.V. (2001). Characteristics of airflow from open windows. Build. Environ. 36, 859-869. https://doi.org/10.1016/S0360-1323(01)00012-9

Jiang, Y., Alexander, D., Jenkins, H., Arthur, R., Chen, Q. (2003). Natural ventilation in buildings: Measurement in a wind tunnel and numerical simulation with large-eddy simulation. J. Wind Eng. Ind. Aerodyn. 91, 331-353. https://doi.org/10.1016/S0167-6105(02)00380-X

Jin, R., Hang, J., Liu, S., Wei, J., Liu, Y., Xie, J., Sandberg, M. (2016). Numerical investigation of winddriven natural ventilation performance in a multi-storey hospital by coupling indoor and outdoor airflow. Indoor Built Environ. 25, 1226-1247. https://doi.org/10.1177/1420326X15595689

Kabanshi, A., Wigö, H., Sandberg, M. (2016). Experimental evaluation of an intermittent air supply system-Part 1: Thermal comfort and ventilation efficiency measurements. Build. Environ. 95, 240-250. https://doi.org/10.1016/j.buildenv.2015.09.025

Krajčík, M., Simone, A., Olesen, B.W. (2012). Air distribution and ventilation effectiveness in an occupied room heated by warm air. Energy Build. 55, 94-101. https://doi.org/10.1016/j.enbu ild.2012.08.015

Larsen, T.S., Heiselberg, P. (2008). Single-sided natural ventilation driven by wind pressure and temperature difference. Energy Build. 40, 1031-1040. https://doi.org/10.1016/j.enbuild.2006. 07.012

Larsen, T.S., Plesner, C., Leprince, V., Carriéet, F.L., Bejder, A.K. (2018). Calculation methods for single-sided natural ventilation: Now and ahead. Energy Build. 177, 279-289. https://doi.org/ 10.1016/j.enbuild.2018.06.047

Martins, N.R., da Graça, G.C. (2016). Validation of numerical simulation tools for wind-driven natural ventilation design. Build. Simul. 9, 75-87. https://doi.org/10.1007/s12273-015-0251-6 Menter, F.R. (2012). Best practice, scale-resolving simulations in ANSYS CFD. ANSYS Germany GmbH. 
Montazeri, H., Montazeri, F. (2018). CFD simulation of cross-ventilation in buildings using rooftop wind-catchers, impact of outlet openings. Renewable Energy 118, 502-520. https://doi.org/1 0.1016/j.renene.2017.11.032

Pan, W., Liu, S., Li, S., Cheng, X., Zhang, H., Long, Z., Chen, Q. (2019). A model for calculating single-sided natural ventilation rate in an urban residential apartment. Build. Environ. 147, 372-381. https://doi.org/10.1016/j.buildenv.2018.08.047

Park, J., Jeong, B., Chae, Y.T., Jeong, J.W. (2020). Machine learning algorithms for predicting occupants' behaviour in the manual control of windows for cross-ventilation in homes. Indoor Built Environ. https://doi.org/10.1177/1420326X20927070

Richards, P.J., Hoxey, R.P. (1993). Appropriate boundary conditions for computational wind engineering models using the $\mathrm{k}-\varepsilon$ turbulence model. J. Wind Eng. Ind. Aerodyn. 46-47, 145153. https://doi.org/10.1016/0167-6105(93)90124-7

Sandberg, M. (1981). What is ventilation efficiency. Build. Environ. 16, 123-135. https://doi.org/ 10.1016/0360-1323(81)90028-7

Tang, Y., Li, X., Zhu, W., Cheng P.L. (2016). Predicting single-sided airflow rates based on primary school experimental study. Build. Environ. 98, 71-79. https://doi.org/10.1016/j.buildenv.2015. 12.021

Tominaga, Y., Mochida, A., Yoshie, R., Kataoka, H., Nozu, T., Yoshikawa, M., Shirasawa, T. (2008). AlJ guidelines for practical applications of CFD to pedestrian wind environment around buildings. J. Wind Eng. Ind. Aerodyn. 96, 1749-1761. https://doi.org/10.1016/j.jweia.2008.02.058

Tzanakis, A. (2014). Duct optimization using CFD software 'ANSYS Fluent Adjoint Solver'. Master's thesis in Automotive Engineering. Department of Applied Mechanics. Division of Vehicle Engineering and Autonomous Systems. Chalmers University of Technology. Goteborg, Sweden.

Visagavel, K., Srinivasan, P.S.S. (2009). Analysis of single side ventilated and cross ventilated rooms by varying the width of the window opening using CFD. Sol. Energy 83, 2-5. https://doi.org/10.1016/j.solener.2008.06.004

von Grabe, J., Svoboda, P., Bäumler, A. (2014). Window ventilation efficiency in the case of buoyancy ventilation. Energy Build. 72, 203-211. https://doi.org/10.1016/j.enbuild.2013.10.006

Walker, R.R., White, M.K. (1992). Single-sided natural ventilation -how deep an office. Build. Serv. Eng. Res. Technol. 13, 231-236. https://doi.org/10.1177/014362449201300407

Wang, H., Chen, Q. (2012). A new empirical model for predicting single-sided, wind-driven natural ventilation in buildings. Energy Build. 54, 386-394. https://doi.org/10.1016/j.enbuild.2012.07. 028

Wang, J., Niu, J., Liu, X., Li, B., Yu, C. (2010). The dispersion in the re-entrance space of a high-rise residential building in the wind tunnel investigation. Indoor Built Environ. 19, 638-647. https://doi.org/ 10.1177/1420326X10386669

Wang, J., Zhang, T., Wang, S., Battaglia, F. (2018). Numerical investigation of single-sided natural ventilation driven by buoyancy and wind through variable window configurations. Energy Build. 168, 147-164. https://doi.org/ 10.1016/j.enbuild.2018.03.015

Wang, T.W., Yin, W., Fu, L.L., Zhang, Z.Y. (2020). Estimation model for natural ventilation by wind force considering wind direction and building orientation for low-rise building in China. Indoor Built Environ. 1420326X20944983. https://doi.org/10.1177/1420326X20944983

Warren, P., Parkins, L.M. (1977). Ventilation through openings on one wall only. In Proceeding of International Centre for Heat and Mass Transfer Seminar "Energy Conservation in Heating, Cooling, and Ventilation Buildings", Washington.

White, M.K., Walker, R.R. (1996). The efficiency of single-sided and cross ventilation in office spaces, Vol. 2, Proc. 17th AIVC Conference - Optimum Ventilation and Air Flow Control in Buildings, Gothenburg, Sweden, pp. 487-496.

Xu, C., Luo, X., Yu, C.W., Cao, S.J. (2020). The 2019-nCoV epidemic control strategies and future challenges of building healthy smart cities. Indoor Built Environ 29, 639-644. https://doi.org/ 10.1177/1420326X20910408

Yik, F.W.H., Lun, Y.F. (2010). Energy saving by utilizing natural ventilation in public housing in Hong Kong. Indoor Built Environ. 19, 73-87. https://doi.org/10.1177/1420326X09358021

Zhou, J., Ye, C., Hu, Y, Zhang, G., Yang, W. (2017). Development of a model for single-sided, winddriven natural ventilation in buildings. Build. Serv. Eng. Res. Technol. 38, 381-399. https://doi.org/10.1177/0143624417699658 